\title{
Selection of Inductor and Snubber Capactor to Optimize the Size and Efficiency of DC-DC Switching Power Converter
}

\author{
N. M. Mahesh Gowda ${ }^{1}$ and S.S. Parthasarathy ${ }^{2}$ \\ ${ }^{1}$ Assistant Professor, Department of Electronics and Communication Engineering, \\ ${ }^{2}$ Professor, Department of Electrical and Electronics Engineering, \\ PES College of Engineering, Karnataka, India \\ E-Mail: nm_maheshg@yahoo.co.in
}

\begin{abstract}
This paper presents a selection of inductor and snubber capacitor in non-isolated synchronous DC-DC switching power converter. The circuit is made to operate in Synchronous Discontinuous Conduction Mode (SDCM)/Forced Continuous Conduction Mode (FCCM) of operation for minimum inductor value, to reduce the size, weight and cost of the converter. The turn off loss of the switch induced by SDCM of operation is minimized by connecting snubber capacitor across the transistor switch. Before the switch is turned $\mathrm{ON}$, snubber capacitor requires certain amount of energy must be stored in the inductor to discharge the capacitor energy [1]. The question is how much capacitor and inductor value is required. A series of MATLAB script are executed to find minimum inductor value for FCCM of operation and to select snubber capacitor for maximum efficiency. Complementary gate signals are used to control the ON and OFF of main and auxiliary switch. SDCM of operation due to complementary control gate signal scheme, minimum turn on loss of the transistor switch and low diode reverse recovery loss are achieved. Thus the Zero Voltage Resonant Transition (ZVRT) of transistor switch is realized, both turn on and turn off loss is minimized and also removes the parasitic ringing in inductor current.
\end{abstract}

Keywords: SDCM, buck, boost, buck-boost, non-isolated, MATLAB script

\section{INTRODUCTION}

Switching DC-DC converters are power electronic circuits which transfer one level of electrical voltage into another level by switching action. These converters are implemented in numerous fields like Uninterrupted Power Supplies (UPS), telecommunication purpose, DC machine drives, aerodynamics, hybrid electric and fuel cell vehicles[2][3], renewable energy system etc. The function of a DC-DC converter is to provide a stable DC output voltage from a given input voltage. The converter is typically required to regulate the DC output voltage given a range of load currents drawn and/or range of input voltage applied. Ideally the DC output is to be clean, that is with ripple current or voltage held below a specified level. Furthermore, the load power is to be delivered from the source with some specified level of efficiency. Power inductor selection is an important step to achieving these goals. Inductance is calculated to provide a cer tain minimum amount of energy storage and to reduce output current ripple. Using less than the calculated inductance causes increased $\mathrm{AC}$ ripple on the DC output. Using much greater or much less inductance may force the converter to change between continuous and discontinuous modes of operation.A smaller inductor value enables a faster transient response; it a lso results in larger current ripple, which causes higher conduction losses in the switches, inductor, and parasitic resistances. The smaller inductor also requires a larger filter capacitor to decrease the output voltage ripple [4]. The parasitic ringing effect due to turn-off loss (due to high switch current) can be minimizing by connecting snubber capacitor across the switch. A snubber is an energyabsorbing circuit used to eliminate voltage spikes caused by circuit parasitic inductance when a switch opens. Design process of snubber circuit for DC-DC converter and six topologies of snubber circuits $(C$, single $C, R C$, single $R C$, $\mathrm{RCD}$, single RCD) were investigated in simulation tests [5]. This paper proposes an inductor and snubber capacitor optimization. A serial of MATLAB script are executed to find the optimum value of snubber capacitor and inductor based on the minimal overall device and switch conduction loss condition for maximum efficiency.

\section{CIRCUIT TOPOLOGY}

A non-isolated synchronous bidirectional switching DC-DC power converter technology is to combine a buck, boost and buck-boost mode of operation.Complementary gate signal control scheme is used to control the ON and OFF of transistor switches. The converter is operated in SDCM of operation such that the inductor size, cost, converter size and weight can be reduced. The SDCM of operation introduces more turn-off loss due to the main switch turn off during twice or higher load current [6]. This is one of the drawback of the inductor size reduction. The inductor current parasitic ringing will be caused by the oscillation of inductor with device output capacitance during turn off period of switch[7]. This issue due to SDCM of operation will affect the efficiency. The snubber capacitor added across the transistor switch is to reduce turn off loss. For zero turn-on loss the energy stored in the capacitor need to be discharged before the switch is turned ON, thus the Snubber capacitor requires certain amount of energy must be stored in the inductor to discharge the capacitor energy before the device is turned on. Thus the Zero Voltage Resonant Transition (ZVRT) of transistor switch is realized. The main advantage of the SDCM of operation due to complementary gating signal control scheme, is minimum 
turn-on loss, thus low diode reverse recovery loss is achieved and also removes the parasitic ringing in inductor current. Thus both turn-on and -off losses are minimized. PID controller is used as a f eedback controller in buck, boost and buck-boost mode of operation with inductor current as a feedback reference [8].

Fig.1 shows the circuit topology. When $\mathrm{V}_{\mathrm{H}}=\mathrm{DC}$ source voltage and $\mathrm{V}_{\mathrm{L}}=0$ voltage, the circuit will act as buck mode with $R_{2}$ act as load and $R_{1}$ is the internal resistance of $V_{H}$. When $\mathrm{V}_{\mathrm{H}}=0 \mathrm{~V}$ and $\mathrm{V}_{\mathrm{L}}=\mathrm{DC}$ source voltage, the circuit is in boost mode with $\mathrm{R}_{1}$ as a load and $\mathrm{R}_{2}$ is the internal resistance of $\mathrm{V}_{\mathrm{L}}$. In buck mode the inductor average current is positive and in boost mode it is negative. In buck-boost mode of operation, $V_{\mathrm{H}}$ and $V_{\mathrm{L}}$ are the source voltage at high side $\left(V_{1}\right)$ and at low side $\left(V_{2}\right)$ voltage respectively, $R_{1}$ is the internal resistance of $V_{\mathrm{H}}, R_{2}$ is the load resistance at low voltage side. $C_{\mathrm{H}}$ and $C_{\mathrm{L}}$ are the input and output capacitors to smooth the load current and load voltage. $Q_{1}$ and $Q_{2}$ are MOSFETs, acts as switches with body diode $D_{1}$ and $D_{2}$ respectively. $C_{1}$ and $C_{2}$ are snubber capacitors. $L$ is the inductor with effective series resistance $R_{\mathrm{LP}}$.

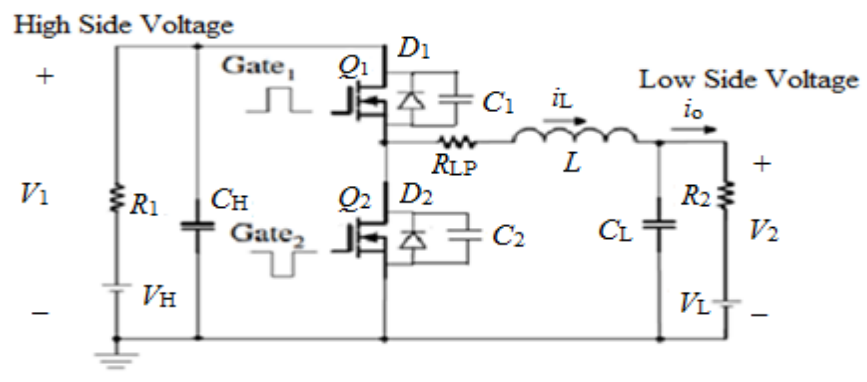

Fig. 1 Circuit topology

\section{INDUCTOR SELECTION}

The gate signal realization of complementary control over soft switching of ZVRT depends upon negative inductor current emergence, that will take place by limiting the inductance less than critical inductor $\left(\mathrm{L}_{\mathrm{cr}}\right)$ value, given in equation (1) [9]. This inductance allows the converter operating under the boundary condition between FCCM and Continuous Conduction Mode (CCM) of operation.

$\mathrm{L}_{\mathrm{cr}}=\frac{1}{2} \cdot \frac{\mathrm{V}_{\text {in }}-\mathrm{V}_{\text {out }}}{\mathrm{P}_{\mathrm{o}}} \cdot \frac{\mathrm{V}_{\text {out }}{ }^{2}}{\mathrm{~V}_{\text {in }}} \cdot \mathrm{T}_{\mathrm{s}}$

Where $V_{\text {in }}$ is the input voltage, $V_{\text {out }}$ is the output voltage, $\mathrm{P}_{\mathrm{o}}$ is output power and $\mathrm{T}_{\mathrm{s}}$ is the switching frequency.
The inductor ripple current $\left(\Delta \mathrm{I}_{\mathrm{L}}\right)$ [10] and the inductor conduction loss $\left(\mathrm{P}_{\mathrm{L}}\right)$ [11] are given in equation (2) and (3) respectively.

$\Delta \mathrm{I}_{\mathrm{L}}=\frac{1}{2} \cdot \frac{\mathrm{V}_{\text {in }}-\mathrm{V}_{\text {out }}}{\mathrm{L}} \cdot \frac{\mathrm{V}_{\text {out }}}{\mathrm{V}_{\text {in }}} \cdot \mathrm{T}_{\mathrm{S}}$

$\mathrm{P}_{\mathrm{L}}=\mathrm{I}_{\mathrm{RMS}_{\mathrm{L}}}^{2} \cdot \mathrm{R}_{\mathrm{LP}}$

Where $R_{L P}$ is the effective series resistance (ESR) of the inductor $\mathrm{L}$ and $\mathrm{I}_{\mathrm{RMS} \_} \mathrm{L}$ is the rms inductor current given in equation (4)

$\mathrm{I}_{\mathrm{RMS} \_\mathrm{L}}^{2}=\mathrm{I}_{\mathrm{L}}^{2}+\frac{\Delta \mathrm{I}_{\mathrm{L}}^{2}}{12}$

Where $\mathrm{I}_{\mathrm{L}}$ is the inductor average current.

TABLE I INDUCTOR SELECTION

\begin{tabular}{|c|c|c|c|c|c|c|c|c|c|c|c|}
\hline \multirow[b]{2}{*}{ Mode of operation } & \multirow[b]{2}{*}{ Case } & \multirow{2}{*}{$\begin{array}{l}V_{H} \\
(\mathbf{V})\end{array}$} & \multirow{2}{*}{$\begin{array}{l}V_{L} \\
(V)\end{array}$} & \multirow{2}{*}{$\begin{array}{l}\mathbf{R}_{1} \\
(\mathbf{\Omega})\end{array}$} & \multirow{2}{*}{$\begin{array}{c}\mathbf{R}_{2} \\
(\boldsymbol{\Omega})\end{array}$} & \multirow{2}{*}{$\begin{array}{c}I^{*} \\
\text { (A) }\end{array}$} & \multirow{2}{*}{$\begin{array}{c}\mathbf{L}_{\mathrm{cr}} \\
(\boldsymbol{\mu H})\end{array}$} & \multicolumn{2}{|c|}{ Boundary Condition } & \multicolumn{2}{|c|}{ FCCM of operation } \\
\hline & & & & & & & & $\begin{array}{c}\Delta \mathbf{I}_{\text {Lcr }} \\
\text { (A) }\end{array}$ & $\begin{array}{l}\mathbf{P}_{\text {Lcr }} \\
\text { (W) }\end{array}$ & $\begin{array}{c}\Delta \mathbf{I}_{\mathrm{L}-10 \mu \mathrm{H}} \\
\mathbf{( A )}\end{array}$ & $\begin{array}{c}P_{\mathrm{L}-10 \mu \mathrm{H}} \\
\text { (W) }\end{array}$ \\
\hline \multirow{4}{*}{ Buck } & 1 & 250 & 0 & $10 \mathrm{~m}$ & 10 & 15 & 39.97 & 15 & 8.77 & 59.96 & 18.88 \\
\hline & 2 & 250 & 0 & $10 \mathrm{~m}$ & 10 & 20 & 19.94 & 20 & 15.60 & 39.89 & 19.17 \\
\hline & 3 & 250 & 0 & $10 \mathrm{~m}$ & 5 & 20 & 29.99 & 20 & 15.60 & 59.98 & 25.19 \\
\hline & 4 & 270 & 0 & $10 \mathrm{~m}$ & 10 & 15 & 44.42 & 15 & 8.77 & 66.64 & 21.42 \\
\hline \multirow{4}{*}{ Boost } & 1 & 0 & 50 & 18 & $10 \mathrm{~m}$ & -12 & 21.79 & 11.79 & 5.60 & 25.70 & 7.16 \\
\hline & 2 & 0 & 60 & 18 & $10 \mathrm{~m}$ & -12 & 23.77 & 11.82 & 5.60 & 28.12 & 7.55 \\
\hline & 3 & 0 & 60 & 18 & $10 \mathrm{~m}$ & -16 & 20.57 & 15.69 & 9.95 & 32.30 & 12.34 \\
\hline & 4 & 0 & 60 & 9 & $10 \mathrm{~m}$ & -12 & 12.65 & 11.82 & 5.60 & 14.97 & 5.85 \\
\hline \multirow{6}{*}{ Buck-Boost } & \multirow[b]{2}{*}{1} & 250 & 110 & $10 \mathrm{~m}$ & 2 & 30 & 18.10 & 30 & 35.10 & 54.30 & 41.24 \\
\hline & & 250 & 110 & $10 \mathrm{~m}$ & 2 & -20 & 25.20 & 20 & 15.60 & 50.40 & 22.02 \\
\hline & \multirow[b]{2}{*}{2} & 250 & 110 & $10 \mathrm{~m}$ & 1 & 30 & 20.51 & 30 & 35.10 & 61.54 & 43.76 \\
\hline & & 250 & 110 & $10 \mathrm{~m}$ & 1 & -20 & 28.80 & 20 & 15.60 & 57.60 & 24.35 \\
\hline & \multirow[b]{2}{*}{3} & 260 & 110 & $10 \mathrm{~m}$ & 2 & 30 & 19.58 & 30 & 35.10 & 58.76 & 42.75 \\
\hline & & 260 & 110 & $10 \mathrm{~m}$ & 2 & -20 & 25.57 & 20 & 15.60 & 51.15 & 22.25 \\
\hline
\end{tabular}


A series of MATLAB script are executed, to find minimum inductor value for FCCM of operation. The results are tabulated in Table 1. The switching time considered is 0.02 ms. From the Table 1, it is observed that, the minimum and maximum inductor value at boundary condition is $12.65 \mu \mathrm{H}$ and $44.42 \mu \mathrm{H}$ and the corresponding inductor power loss are 5.6 Watt and 8.77 Watt respectively. Therefore the required minimum inductor value to make the converter to operate in FCCM of operation for different test cases in different modes of operation must be less than $12.65 \mu \mathrm{H}$. Hence 10 $\mu \mathrm{H}$ is considered in circuit topology module. This $10 \mu \mathrm{H}$ inductor is considered as optimal unique inductor value which ensures FCCM of operation in all the three modes of operation in different test cases. This inductor conduction loss lies in the range of 5.85 Watt to 43.76 Watt for different test cases in FCCM of operation.

\section{SNUBBER CAPACITOR SELECTION}

To minimize the turn-off loss in larger extent, larger snubber capacitor is required which minimizes drain current during turn-off period, but it may lead to more turn-on loss, because it will not discharge fully during turn-on period. The snubber capacitor is selected in such a way that it must minimize total turn-on, turn-off and snubber capacitor loss. During switch turn ON time, capacitor voltage fully discharges when the inductor stored energy is greater than the capacitor energy storage ability. This leads to minimum turn ON loss. The charge balance of $\mathrm{CV}^{2}$ and $\frac{1}{2} \mathrm{LI}_{\mathrm{L}}^{2}$ is used for snubber capacitor design as given in equation (5) for minimum turn ON loss

C. $\mathrm{V}^{2} \leq \frac{1}{2}$. L. $\mathrm{I}_{\mathrm{L}}^{2}$

The above equation is modified for snubber capacitor value as given in equation (6) to minimize switching turn on loss as well as snubber capacitor loss.

$\mathrm{C} \leq 0.5 . \mathrm{L} \cdot\left(\frac{\mathrm{I}_{\mathrm{L}}}{\mathrm{V}}\right)^{2}$

Where $\mathrm{C}=$ snubber capacitor, $\mathrm{V}=$ capacitor voltage, $\mathrm{L}=$ Inductor and $\mathrm{I}_{\mathrm{L}}=$ inductor average current.

The power loss in snubber capacitor is given in equation (7) [12]

$\mathrm{P}_{-} \mathrm{C}_{\mathrm{SNU}}=\frac{1}{2} \cdot \mathrm{C}_{\mathrm{s}} \cdot \mathrm{V}_{\mathrm{DS}}^{2} \cdot \mathrm{f}_{\mathrm{sW}}$

Where $C_{s}$ is the snubber capacitor, $V_{D S}$ is the maximum voltage across the switch and $f_{s w}$ is the switching frequency

The snubber capacitor is optimized for minimum power loss across it and for minimum switching turn on loss to improve the efficiency. For this, series of MATLAB script are executed and results are tabulated in Table 2.

\begin{tabular}{|c|c|c|c|c|c|c|c|c|}
\hline Mode of operation & Case* & $\begin{array}{c}V_{1}=V_{D S} \\
(V)\end{array}$ & $\begin{array}{l}\mathrm{C}_{\mathrm{SNU}} \\
(\mathrm{nF})\end{array}$ & $\begin{array}{c}E_{-} C_{\text {SNU }} \\
{\left[C_{s} \cdot V_{1}^{2}\right] \text { (Joule) }}\end{array}$ & $\begin{array}{l}\text { E_15nf } \\
\text { (Joule) }\end{array}$ & $\begin{array}{c}\text { E_10 } 1 \text { H } \\
{\left[\frac{1}{2} . L . I_{L}^{2}\right] \text { (Joule) }}\end{array}$ & $\underset{(W)}{P_{-} C_{S N U}}$ & $\underset{\text { (W) }}{\text { P_15nf }}$ \\
\hline \multirow{4}{*}{ Buck } & 1 & 249.90 & 18.01 & 0.0011 & $9.36 \mathrm{e}-4$ & 0.0011 & 56.25 & 46.84 \\
\hline & 2 & 249.83 & 32.04 & 0.002 & $9.36 \mathrm{e}-4$ & 0.002 & 100 & 46.81 \\
\hline & 3 & 249.91 & 32.02 & 0.002 & $9.36 \mathrm{e}-4$ & 0.002 & 100 & 46.84 \\
\hline & 4 & 269.91 & 15.44 & 0.0011 & 0.0011 & 0.0011 & 56.25 & 54.64 \\
\hline \multirow{4}{*}{ Boost } & 1 & 102.90 & 67.98 & $7.2 \mathrm{e}-4$ & $1.58 \mathrm{e}-4$ & $7.2 \mathrm{e}-4$ & 36 & 7.94 \\
\hline & 2 & 112.91 & 56.47 & $7.2 \mathrm{e}-4$ & $1.91 \mathrm{e}-4$ & $7.2 \mathrm{e}-4$ & 36 & 9.56 \\
\hline & 3 & 130.02 & 75.70 & 0.0013 & $2.53 \mathrm{e}-4$ & 0.0013 & 64 & 12.68 \\
\hline & 4 & 79.84 & 112.94 & $7.20 \mathrm{e}-4$ & $9.56 e-5$ & $7.2 \mathrm{e}-4$ & 36 & 4.78 \\
\hline \multirow{6}{*}{ Buck-Boost } & \multirow{2}{*}{1} & 249.79 & 72.11 & 0.0045 & $9.35 \mathrm{e}-4$ & 0.0045 & 225 & 46.79 \\
\hline & & 250.05 & 31.98 & 0.0020 & $9.37 \mathrm{e}-4$ & 0.0020 & 100 & 46.89 \\
\hline & \multirow[b]{2}{*}{2} & 249.82 & 72.09 & 0.0045 & $9.36 \mathrm{e}-4$ & 0.0045 & 225 & 46.81 \\
\hline & & 250.07 & 31.98 & 0.0020 & $9.38 \mathrm{e}-4$ & 0.0020 & 100 & 46.90 \\
\hline & \multirow[b]{2}{*}{3} & 259.80 & 66.67 & 0.0045 & 0.0010 & 0.0045 & 225 & 50.62 \\
\hline & & 260.05 & 29.57 & 0.0020 & 0.0010 & 0.0020 & 100 & 50.72 \\
\hline
\end{tabular}

From equation (7) the power loss in snubber capacitor is directly proportional to snubber capacitor value, drain to source voltage of MOSFET and switching frequency, so it is better to select minimum value of snubber capacitor for maximum efficiency.

From the Table 2, it is observed that, the minimum snubber capacitor value for maximum capacitor voltage is $15.44 \mathrm{nF}$ and the corresponding power loss through it is 56.25 Watts.
To satisfy equation (5), for all different test cases in different modes of operation, a snubber capacitor of $15 \mathrm{nF}$ is considered in circuit topology module, which is considered as optimal unique snubber capacitor value for all the three modes of operation. This ensures, the capacitor fully discharge before the switch is turn on, which minimizes the switch turn-on loss. 


\section{CONCLUSION}

The paper presents a high-efficiency bidirectional nonisolated synchronous DC-DC switching power converter. The converter is made to operate in Forced Continuous Current Mode (FCCM)/ Synchronous Discontinuous Current Mode (SDCM) of operation, to minimize the inductor value, size, cost and weight of the converter. The turn off loss of the switch induced by SDCM of operation is minimized by connecting snubber capacitor across the transistor switch. A complementary gate signal control scheme is used to turn on and off the transistor switch. Antiparalleled diode of the transistor switch helps to discharge the capacitor. SDCM of operation due to complementary control gate signal scheme, minimum turn on loss of the transistor switch and low diode reverse recovery loss are achieved. Thus the Zero Voltage Resonant Transition (ZVRT) of transistor switch is realized, both turn on and turn off loss is minimized and also removes the parasitic ringing in inductor current. A serial of MATLAB script are executed to find the optimum value of snubber capacitor and inductor based on the minimal overall device and switch conduction loss condition.

\section{REFERENCES}

[1] X. Huang, X. Wang, T. Nergaard, J. S. Lai, X. Xu and L. Zhu, "Parasitic Ringing and Design Issues of Digitally Controlled High Power Interleaved Boost Converters", IEEE Trans. Power Electron, Vol. 19, No. 5, pp.1341-1352, Sep. 2004.

[2] Jih-Sheng Lai and D. J. Nelson, "Energy management power converters in hybrid electric and fuel cell vehicles," in Proceedings of IEEE, Industrial Electron, Taipei, Taiwan, Vol. 95, No. 4, pp. $766-$ 777, April 2007.
[3] Sanjay Havanur, "Snubber Design for Noise Reduction in Switching Circuits", Alpha and Omega Semiconductors, Application Note, pp. AN 100-1 - AN 100-3, May 2007.

[4] Junhong Zhang, Jih-Sheng Lai, Rae-Young Kim, and Wensong Yu, "High-Power Density Design of a Soft-Switching High-Power Bidirectional dc-dc Converter",IEEE Trans. Power Electronics, Vol. 22, No. 4, pp. 1145-1153, July 2007.

[5] Hosein Farzanehfard, Dawood Shekari Beyragh and Ehsan Adib, "A Bidirectional Soft Switched Ultracapacitor Interface Circuit for Hybrid Electric Vehicles", Energy Conversion and Management, Elsevier, pp. 3578-3584, 2008.

[6] Arvind Raj, "Calculating Efficiency", Texas Instruments, Application Report, pp. 1-6, SLVA390-February 2010

[7] Premananda Pany, R.K. Singh and R.K. Tripathi, "Bidirectional DCDC converter fed drive for electric vehicle system", International Journal of Engineering, Science and Technology, Vol. 3, No. 3, pp. 101-110, 2011.

[8] Ebrahim Babaei, Mir Esmaeel Seyed Mahmoodieh and Mehran Sabahi, "Investigating Buck DC-DC Converter Operation in Different Operational Modes and Obtaining the Minimum Output Voltage Ripple Considering Filter Size",Journal of Power Electronics, Vol. 11, No. 6, pp. 793-800, Nov. 2011.

[9] R. Ilker Kayaalp, Tugce Demirdelen and Mehmet Tumay, "Modelling and Analysis of Bidirectional DC-DC Converter", International Journal for Innovation Education and Research, Online-ISSN: 24112933, Vol. 3, No. 11, pp. 16-30, Dec 2015.

[10] Lukasz J. Niewiara, Michał Skiwski and Tomasz Tarczewski, "Experimental study of snubber circuit design for $\mathrm{SiC}$ power MOSFET devices", Computer Applications in Electrical Engineering, Vol. 13, pp. 120 - 131, 2015.

[11] Shafinaz A. Lopa, S. Hossain, M. K. Hasan and T. K. Chakraborty, "Design and Simulation of DC-DC Converters",International Research Journal of Engineering and Technology, Vol. 03, No. 1, pp. $63-70,2016$.

[12] N MMahesh Gowda and Dr. S S Parthasarathy, "Optimization of Synchronous Non-Isolated Bidirectional DC-DC Switching Power Converter", Asian Journal of Electrical Sciences, ISSN: 2249- 6297, Vol.5, No.2, pp. 33-43, July-Dec 2016 